\title{
The Indigenous Concept of Sexuality in African Tradition and Globalization
}

\author{
Okafor Samuel Okechi* \\ Department of Sociology/Anthropology, University of Nigeria, Nigeria
}

Submission: July 20, 2018; Published: September 18, 2018

*Corresponding author: Okafor Samuel Okechi, Department of Sociology/Anthropology, University of Nigeria, Nsukka, Nigeria; Email: samuelokey200@gmail.com

\section{Abstract}

Across the human societies, the concept of sex and sexual relationship is attached with some degree of sacredness and in some cases, can be classified as a taboo if some rules guiding such activity is ignored or violated. African societies in particular, at various degrees, have an understanding of sexual relationship as a sacrosanct factor to the image of a group, and a respectable phenomenon which every member of the group must adhere to the rules guiding them. However, the era of culture contact has left an indelible mark on the understanding and perception of sexual relationship among the African societies. This paper analyses the trends in the perception of sex and sexual relationship among the African societies, in the face of cultural globalization using, the available Ethnographic literatures and other emerging issues. Though the wave of cultural globalization is so enormous to have sunk the ships of most African Traditional Cultures, the paper suggested a common ground for the accommodation of the concept of sex and sexual relationship between the African Traditional Culture and the emerging global culture.

Keywords: Sexual relationship; African Traditional culture; Cultural globalization; Sacredness; Taboos

\section{Introduction}

From all perspectives in the explanation of the origin and development of humanity, one thing had remained constant in all analysis "sex and sexual relationship". Sex and sexual relationship remain the bedrock on which the multiplication of human beings and lower infra sentient beings rest. It may be expressed through the mentioning of the opposite sexes (man and woman) or through other concepts, which captures the invisible forces, which pull together opposite sex. Whichever way, the underlying message in the explanation of human multiplication from the ancient time, is sexual union. Beyond the primary function of sexual union, which is for procreation, sexual union which naturally occur as a result of opposite sex attraction had other functions in the lives of individuals especially as the humanity continue to advance in knowledge and in the freedom of individuals rights and liberty.

Societies world over have different interpretations and values for sexual union such that, while others see it as sacred and impinging on group's norms and value, many more see it as an individual affair which has little or nothing to do with group norms especially in the modern societies. Irrespective of the fact that sexual union has become individual affair in the industrialized nations, as it is gradually becoming an individual affair in such places as the developing nations, we have not lost the sight of the fact that it was once respected among these societies (Industrialized nations) and is still with some level of sanctity in most developing nations in the African continents. However, the African continent as a unique continent in respect to culture and traditional norms and values, is one of the continents where many nations still place value on human sexuality and sexual union as a group order than individual matter. According to Beidelman [1], "there is so much pressure among the Kenyans (Kikuyu) to observe the proper conduct after initiation which grants the male youth access to female youth irrespective of the fact that they were allowed to express sexual feelings in the course of their being together" (227).

Although among the African nations especially the East African nations, there is what an alien observer may consider sexual freedom among the males and females and by implication, some level of recklessness, all these are regulated through certain consistent means. Appiah-Kubi [2] observed that among the Akan in Ghana, Nyakyusa in Tanzania, Kaguru in Tanzania, Kamba and Kikuyu in Kenya, there were relatively a system of pressure from both the peers and the elders to control individual excesses in sexual activities irrespective of the fact that it (sex) is seen as a normal exercise which every grown-up youth should aspire to involve himself in it.

Meanwhile, before the Eurasian contact with Africa, the issue of human sexuality was well recognized as individual right which is subject to group norms and values. The elderly members of the society initiated the individual members of the society into the concepts and the act of human sexuality through a well-organized and consistent socialization process. The interruption of the African traditional system by the Eurasian contact succeeded in redefining the concept of sexuality and sacredness shifting the emphasis from group to individual erroneous perception of sex 


\section{Global Journal of Reproductive Medicine}

and sexual relationship, thereby creating a wrong impression about sexuality and sexual relationship. Consequently, the same instigators of wrong orientation of sexual relationship reversed in another dimension to appear through the loophole they created (wrong impression about human sexuality) to instigate another catastrophe in the concept of cultural globalization especially as regards to human sexuality among the African societies. Indeed, they claim to be spreading the message about the freedom of individuals to sexuality and sexual orientation, these were what they destroyed in the past through their religious and cultural proselytizers, who knew nothing about the African traditional societies.

Nonetheless, this paper on the basis of ethnographic, and historical literature aim to unravel the controversy about human sexuality in African context in the colonial and post colonial era, which was the outcome of imposition of foreign values and misinterpretation of the pre-colonial African way of life.

\section{Sexuality and sexual relationship in African traditions}

Sex through which sexuality and sexual relationship is derived, is a social construction, which aimed at capturing the physiological differences in human beings which are responsible for the roles in the reproduction function. One is male or female on the ground of the types of gamete, which they release in the process of intercourse for conception to take place. The new penguin English dictionary by way of definition gave a picture of what sex is for some level of clarification and alignment and differentiation towards, and out of other concepts about human physiological and social activities. Sex is the condition of being male or female into which organisms are divided on the basis of their reproductive role notably the type of gamete produce.

Sexuality based on the meaning of sex further expanded the implication of being male or female in the biological concept of it. Amanze captured this in an attempt to define the human sexuality. According to Amanze [3], "sexuality is the reproductive mechanism as well and the basic biological drive that exists in all species and can encompass sexual intercourse and sexual contact in all its forms; It is the condition of having a sexual nature of being either male or female and of experiencing sexual desire" (2).

In a more comprehensive manner, world health organization maintained that sexuality is a central aspect of being human throughout life and encompasses sex, gender identities and roles, sexual orientation, eroticism, pleasure, intimacy and reproduction. Sexuality is experienced and expressed in thought fantasies, beliefs, attitudes, values, behaviours, practices, roles and relationships. While sexuality can include all of these dimensions, not all of them are always experienced or expressed. It's influenced by the interaction of biological psychological, social, economic, political, religious and spiritual factors.

Although the definitions seem so good and convincing, we cannot quickly forget that concepts and their usage cannot be applicable in all contexts and by implication, may not capture all the meaning, values and attitudes, which social groups attach to certain phenomena. Borrowing from Max Weber's theoretical legacy, "vestehem and the ideal type", we are invited to understand that the social phenomena and even other phenomena, which interact with man and are involved in by man within his environment, are all subject to his understanding and the picture he gives to them. By implication, following the social evolutionary theoretical framework, concepts such as sex mean different things to different social groups and become clearer in their norms and value system as experiences and circumstances subjected them to further conviction.

In view of the above, the concept of sexual relationship had layers of meaning in the African context and value system. To appreciate this, the way different social groups within the continent see it and what they do about it, is the path to understanding it. Before the European and Asian assaults on the African traditional system, what was captured in the modern day intellectual jingles as "sexuality", can be found deep in the folktales and other oral traditions of the African societies. Evans-Pritchard reported an array of evidences that many African societies had collective expression of obscenity, which was also public such as in the ritual ceremonies, traditional songs and dance among the Zulu people of South Africa, Kikuyu in Kenya, Massai in Tanzania, Mende in Sierraleone, Bechuama in Niger, Pondo and Lokele in Kenya etc [4].

Contrary to the view or imagination that the popularity of opposite sex interaction would have resulted to indiscriminate sexual activity especially premarital sexual union, there were stringent unwritten rules, which guided and enforced discipline among the members of the society. By way of exhibiting an evidence of a social group who have grown past the level of lower infra sentient being (in the evolutionary scale), that exhibit sexual libido instinctively, the African traditional society though acknowledge and attribute value to sexual union, still observe and maintain the sanctity of sexual union. For instance, in some East African societies where a foreigner may define as having a strong passion for sex, there are indications that failure to adhere to the rules that guide sexual union was an offence against even the society as a whole. According to Ahlberg [5], "the openness with which sexuality is expressed does not necessarily mean that sexual activity is indiscriminate among the African societies especially, in the Eastern part.

The problem arises where sexuality is evaluated using foreign moral formulation" (143). In a similar strand, Equiano writing back in the 16th century indicated that Among the Igbo of Nigeria, the female child is betrothed to a male child while they are young, with a degree of freedom among the youth to understand the concept of human sexuality. Nevertheless, this did not guarantee the abuse of the sanctity of sexual union until proper marriage. When any individual is caught in the act of socially unacceptable sexual activity especially, a married woman, execution was applied to heal the wound which such act may have caused the societal dignity" [6]. 


\section{Global Journal of Reproductive Medicine}

The value for sex and at the same time respect attached to it by the African societies before the European contact with the African traditional culture, was not as a result of primitiveness (if there is any situation which can capture such coinage), however it was the evidence of developed human social group with a harmonious coexistence. In the evolutionary parlance, development per se is not only on the type of material social fact as Durkheimian theoretical doctrine opined, but more of the non-material social facts which reflect themselves on the value system of a social group which differentiate them from other lower animals.

Sex, human sexuality and all the pleasures there to, are viewed as indisputable part of human nature however, in African society, the right of individuals and the social group in the matter of sexual union are all respected. While the individual has the right to know and explore it the social group have the right to maintain their collective conscience in what is good for the image of the society.

\section{The concept of taboo, sacredness and the misguided generation}

Taboo and sacredness are the two concepts, which capture for social scientific convenience, the idea and belief, that certain things are on the extreme side of avoidance in the value system of a social group. It may or may not be categorically mentioned that an object or concept is sacred or a taboo in a particular situation, but the way people view and respond to such things may suggest so. Perhaps, it is the incest and religious objects among different social groups world over that have received such a categorical pronunciation. However, it is seen or recognized, the concept of taboo and sacredness here for the purpose of the present work, is to create the picture of the aftermath of colonialist concept of sex among the African societies, which further distanced Africans away from their own value system and by implication raised a confusion, which devastated the group.

The concept of taboo and sacredness, which later enshrined the issue of human sexuality among the traditional Africans, can be attributed to the European Christian missionaries who measured the degree of repentance with the extent of rejection of one's traditional custom and value. Due to the increasing difficulties faced by the Christian theologies in Europe as a result of the domination of science such as Darwinism, Marxism and Freudianism within the social atmosphere, the Christian missionaries who found no accommodation within the social domain of the European community sought for a practicing ground for their faith and new converts.

According to Preston, "by 1900, in England, few resources for a social sanctioning ethic were available to the Church of England, and half the church goers had deserted the church" (65). Similarly, Beidelman [1] reported that, the introspective tendencies particularly associated with the evangelical revival in Britain, leading to the founding and expansion of the church missionary society may have been a reaction to the turmoil of the industrial revolution. In Africa this led to the establishment of missionary settlements isolated from the supposed potential contamination of unconverted heathens and worldly Europeans (91 - 4).
This situation involving Africa was not without consequences. This is because of the fact that meeting with entirely a new cultural group they do not know anything about, coupled with racial sentiments and concept of purity, there were bound to be complications. Thus, Ahlberg [7] recorded

That missionaries who ran away from modern western life, rejecting it as contradictory to their own values, thus sought to reconstruct in Africa a new Christian society clearly impracticable in Europe and America; In this sense, missionaries demanded a level of Christian conduct beyond what they had never experienced among ordinary people at home (228).

To further complicate the issue of value and custom, the competition among the erstwhile missionaries from different denominations coupled with the encroachment of Islam from the Asian side introduced confusing measures in interpreting moral values and acceptable norms especially, as regards to human sexuality.

The implication of Eurasian assault on the African traditional system particularly, the concept of sex and human sexuality, was the subsequent confusion about what made such concepts among the local indigenes derogatory one. This led to the mystification of the concept of sex and human sexuality as "sacred" and "taboo" in the subconscious mind of the indigenous people. The concept of sex and human sexuality was later enshrined in secrecy such that anything about the human sexuality became derogatory in public statement. Contrary to the consistent orientations and sex education among the indigenous African people before the foreigners came in, everything associated with sex and human sexuality including the sexual organs, were deemed derogatory in human interaction especially among the children and the youth.

According to Michugu Kiiru [8], Among the Kikuyu in Kenya, there are taboos that regulate words that must not be discussed in public about human sexuality. Regarded as obscene, the words, as well as the subjects, more often than not centre on or revolve around human genitals, sexual desire, or act; Forbidding their indiscriminate use, the taboos seek to make sex, on which the reproduction of society depends, sacrosanct (22).

This show the opposite of the Kikuyu indigenes who represented in a wide range the Eastern Africa where sex and human sexuality were freely discussed and children properly educated on sexual matters, before the coming of the Europeans. Ikpe [9] also recorded that in the 20th century.

It was a taboo to discuss sexual matters in front of children until they were ready for their passage to adulthood. Although children recognised differences between the genders, they were not supposed to know what the usefulness of such differences was for, except with regard to the allocation of household roles; They were aware that women brought babies but how that actually came about was kept a secret $(19-20)$.

In a social setting where everyone is accustomed to collective conscience and group value system, whatever that finds its way 


\section{Global Journal of Reproductive Medicine}

into the existing value system automatically hold the group in ransom. In addition, such a situation may likely encourage high level of pretence in order to appear innocent and righteous before what the group generally accepted. Due to the Eurasian religious moral value system which sneaked into the African traditional value system on the issue of sex and human sexuality, the issue of sex and sexuality were enshrined in secrecy, teaching the children and the youth about sex and talking about sex in the public became derogatory. Making sexual matters appear in an inverse form in people's understanding (or camera obscurer in Marx's theoretical parlance) coupled with the fact that sex and sexuality is an instinctive aspect of human beings, the youth became uncontrollable by the parents and the society even the married men and women who have to satisfy their sexual feelings by all available means. So that, people tried to appear innocent before the imported religious moral value on sex and do some unimaginable things (sexually) behind the scene.

\section{Sexuality, cultural globalization and individual instinctive drives:}

Globalization which had globalism as its doctrinal foundation cut across all human activities and geographical settings in its aim of unifying, the world into one whole concept and ideology. As Obasi Igwe [10] defined it, "It is both a process and movement of bringing everything, beginning with the economy, into the "world" standards, actually western system, and consequent cultivation of a common but unequal economic, trade, social, military-strategic, and political culture" (175). Cultural globalization focuses on the possibility of bringing the whole world into one whole framework, which will be a substantive measure for moral and other cultural value system. Specifically, globalization favours the culture of the dominating civilizations to the detriment of the developing societies. Meanwhile sexuality and human instinct are the two sacrosanct factors, which may complicate the reality of group value system if allowed to run on individual determination. Borrowing from Freudian analytical framework, human instinctive behaviour involves the Id, ego and super ego.

These three subsets are all subject to the environment and the value system. Remove socialization, you will see that man is not far from the lower infra-sentient beings that move and act spontaneously. In Freudian analysis, id perfectly represents the nature of man outside socialization and established norms and value system. For our interest here, globalization as we know before now carries with it, a numerous confusions and contradictions. Though it is being championed by the Western Europe and North America, we are yet to isolate the element of cultures in these societies, which can perfectly define what "standard moral value" is. We may call it industrialization, modernity, post modernity or even jet age however, the questionable thing about all these is the continuous vulnerability of the collective value system to individual instinctive drive in the name of human right agenda and individual freedom among these societies. Though I may be in dilemma to specifically define what human right is, without running into difficulty with already established popular idea about it, at least, individual human right cannot be meaningful with the group value system, which granted it. Whatsoever it looks like, my interest for delving into such concept was to create a picture of the relationship between the concepts of human right in the modern day civilized societies and the collective value system.

Meanwhile, the cultural globalization, which is being championed by Western Europe and North America, has some of these weaknesses to export to other societies who fall prey to such illicit agenda. With respect to human sexuality, the erstwhile campaigner for cultural globalization have made their system vulnerable to individual instinctive drive which had even resulted to some level of chaos among them.

The age of consent to sex which encouraged premarital sexual activity, is moving towards the extreme side, it is presently at 15 years in most parts of these societies (North America and Europe). In some of them, 14 and 12 years are being considered. As the individual instinctive drive increases its boundary with the collective value system under the umbrella of individual human right, so man is gradually retrogressing towards lower infra sentient beings living on spontaneous drives. Writing under the concept of what he called plastic sexuality; Giddens [11] argues that in the most recent phase of modernity, the nature of intimate relationships has undergone profound changes. Virginity for women is no longer prized and few women are virgins on their marriage day. Plastic sexuality has developed. With plastic sexuality, sex can be freed from its association with childbirth altogether. People have much greater choice over when, how often and with whom they engage in sex [12].

The reckless sexual attitude among the individuals in the civilized nations who are championing the cultural globalization such as United States of America and Western Europe, have moved to the extreme and created some level of unintended consequences. For instance, Associate press in connection with CDC reported that about 1.06 million abortions were conducted in 2011 of which $1 / 3$ were from never married females. $12 \%$ of all the abortions were because of problems with relationships among unmarried youth while, $11 \%$ resulted from the lady in question being too young to give birth to a child.

From January to November (2015), world health organization indicated to have recorded more than 36.7 million abortions across the globe of which the large chunk of it is from the so called civilized societies and mostly among unmarried. All these are with other complications in terms of human health and moral value in general [13].

We are not disputing the civilization status of the North America, Western Europe and their allies elsewhere as envious however; the high level of moral degeneration, which are now encroaching into other aspects of humanity in terms of damage, raises some levels of concern. Imposing such unjustifiable morality on other societies such as Africa will be more terrible than the earlier catastrophe caused by the religious cultural proselytizers who came with the influence of colonialism and acclaimed civilization agenda [14]. 


\section{Global Journal of Reproductive Medicine}

\section{Conclusion}

Human sexuality and sexual relationship has manifested itself as physiological cum cultural phenomena. Physiological here in the sense that it is a naturally occurring urge for pleasure. On the other hand, it is cultural phenomenon due to the organization of human society which create a moral value system that determine how individual members of the society participate in any form of relationship or activity especially as regards to sexual relationship. In view of this, every society especially the African societies, have gradually developed a moral value system which guides and determine what is permissible in the quest to satisfy sexual urges and what is obtainable in terms of human sexuality [15].

Although the religion-cultural proselytizers manipulated the African traditional value system specially the issue of sex and sexuality in the subconscious mind of the indigenous people, thereby creating unfounded concept of taboo and sacredness in connection with sexuality; allowing the imposition of more devastating moral value on African society in the name of cultural globalization, will reduce the African societies to a mere conglomeration of lower infra sentient beings without culture.

\section{Recommendations}

In view of the pre-colonial concept of sexuality among African societies and the subsequent modifications by the colonial agents, the following strategies are recommended for proper changes in the interest of African societies.

I. Sex and sexuality matters should be demystified among the parents in order for them to properly teach their wards the does and don't about sexual relationship.

II. The educational system should incorporate sexual issues in the curriculum at certain stages to help the African youth learn proper things about human sexuality and its implications to the individual and the society.

III. The religious organizations and the custodians of African traditions should detach sacredness and taboo placed on the knowledge about human sexuality to enable the youth come out of their hiding place on the issue of sex and sexual relationship and appreciate such in line with the traditional value system.
IV. Precaution should be taken while defining human right by the policy makers in respect to sexuality matters in order to save the African societies from retrogression towards individual instinctive drives.

\section{References}

1. Costabile RA, Spevak M (2001) Characterization of patients presenting with male factor infertility in an equal access, no cost medical system. Urology 58(6):1021-1024.

2. Gilany K, Mani Varnosfaderani A, Minai Tehrani A, Mirzajani F, Ghassempour A, et al. (2017) Untargeted metabolomic profiling of seminal plasma in nonobstructive azoospermia men: A noninvasive detection of spermatogenesis. Biomed Chromatogr 31(8).

3. Gilany K, Jafarzadeh N, Mani Varnosfaderani A, Minai Tehrani A, Sadeghi MR, et al. (2018) Metabolic Fingerprinting of Seminal Plasma from Non-obstructive Azoospermia Patients: Positive Versus Negative Sperm Retrieval. J Reprod Infertil 19(2):109-114.

4. Batruch I, Smith CR, Mullen BJ, Grober E, Lo KC, Diamandis EP, et al. (2012) Analysis of seminal plasma from patients with non-obstructive azoospermia and identification of candidate biomarkers of male infertility. J Proteome Res11(3): 1503-1511.

5. Buckett W, Lewis Jones D (2002) Fructose concentrations in seminal plasma from men with nonobstructive azoospermia. Arch Androl 48(1): 23-27.

6. Obrosova IG, Stevens MJ (1999) Effect of dietary taurine supplementation on GSH and NAD (P)-redox status, lipid peroxidation, and energy metabolism in diabetic precataractous lens. Invest ophthalmol Vis Sci 40(3):680-8.

7. Vogel R, Wiesinger H, Hamprecht B, Dringen R (1999) The regeneration of reduced glutathione in rat forebrain mitochondria identifies metabolic pathways providing the NADPH required. Neuroscience letters. 275(2): 97-100.

8. Bhardwaj A, Verma A, Majumdar S, Khanduja K (2002) Status of vitamin $\mathrm{E}$ and reduced glutathione in semen of oligozoospermic and azoospermic patients. Asian J Androl 2(3): 225-228.

9. Tang W, Martin KA, Hwa J (2012) Aldose reductase, oxidative stress, and diabetic mellitus. Front Pharmacol 3: 87.

10. Gilany K, Minai Tehrani A, Savadi Shiraz E, Rezadoost H, Lakpour N (2015) Exploring the human seminal plasma proteome: an unexplored gold mine of biomarker for male infertility and male reproduction disorder. J Reprod Infertil 16(2): 61-71.

11. Uhlen M, Oksvold P, Fagerberg L, Lundberg E, Jonasson K, et al. (201) Towards a knowledge-based human protein atlas. Nat Biotechnol 28(12):1248-1250.

Your next submission with Juniper Publishers
will reach you the below assets
- Quality Editorial service
- Swift Peer Review
- Reprints availability
- E-prints Service
- Manuscript Podcast for convenient understanding
- Global attainment for your research
- Manuscript accessibility in different formats
( Pdf, E-pub, Full Text, Audio)
- Unceasing customer service
Track the below URL for one-step submission
https://juniperpublishers.com/online-submission.php

